\title{
Phenology of the Western Cherry Fruit Fly (Diptera: Tephritidae) in Utah and Washington
}

\author{
VINCENT P. JONES, ${ }^{1}$ DIANE G. ALSTON, JAY F. BRUNNER, ${ }^{2}$ \\ DONALD W. DAVIS, AND MARK D. SHELTON ${ }^{3}$ \\ Department of Biology, Utah State University, Logan, Utah 84322-5305
}

\begin{abstract}
Ann. Entomol. Soc. Am. 84(5): 488-492 (1991)
ABSTRACT The flight period of the western cherry fruit fly, Rhagoletis indifferens Curran, was investigated in Utah tart cherry, Prunus cerasus L., orchards from 1983 to 1989 and in Washington sweet cherry, Prunus avium L., orchards between 1982 and 1988. In Utah, flies were first detected on 31 May 1989, but the average time of first detection was 9 June across nine site-years. In Washington, the first fly was detected on 23 May 1988, with an average first detection time of 1 June in the three site-years. On a degree-day (DD) scale (lower threshold of $5^{\circ} \mathrm{C}$ and no upper threshold), detection of the first fly averaged $573 \pm 19.0 \mathrm{DD}$ $(\bar{x} \pm \mathrm{SEM})$ in Utah and $592 \pm 42.1 \mathrm{DD}$ in Washington. A degree-day model using the combined data for Utah and Washington consistently predicted emergence for all but one Utah site without synchronization of the model based on capture of the first fly.
\end{abstract}

KEY WORDS Insecta, Rhagoletis indifferens, cherry, IPM

THE WESTERN CHERRY FRUIT FLY, Rhagoletis indifferens Curran, is the major pest of cherries in the western United States (AliNiazee 1978, Frick et al. 1954). In Utah, the pest complex faced by tart cherry, Prunus cerasus L., growers was dramatically changed by the introduction of the western cherry fruit fly and the apple maggot, Rhagoletis pomonella (Walsh), in 1980 and 1983 , respectively (Davis \& Jones 1986). This has prompted an interest in developing IPM programs for tart cherries that incorporate both apple maggot and western cherry fruit fly components (Jones 1988, Jones \& Davis 1989, Jones et al. 1989).

Previous work on western cherry fruit fly phenology has come almost exclusively from Oregon and Washington. Van Kirk \& AliNiazee (1981) calculated that $8.3^{\circ} \mathrm{C}$ was the lower threshold for development, and Brown \& AliNiazee (1977) determined the effect of different lengths of cold period on adult emergence in the laboratory. Frick et al. (1954) and AliNiazee (1976) observed adult emergence in the field, and AliNiazee (1979) and Stark \& AliNiazee (1982) validated computer models used to predict various aspects of insect phenology important in pest management.

Preliminary studies in Utah suggested that $R$. indifferens emerged later than predicted by AliNiazee (1979). The data also showed that adults were active in Utah up to one month longer than reported by Frick et al. (1954). These studies were therefore initiated to determine the emergence pe-

\footnotetext{
' Current Address: Department of Entomology, University of Hawaii, 3050 Maile Way, Room 310, Honolulu, Hawaii 96822

${ }^{2}$ Tree Fruit Research Center, Washington State University, 1100 North Western Avenue, Wenatchee, Wash. 98801.

${ }^{3}$ Current Address: Crop Science Department, California Polytechnic State University, San Luis Obispo, Calif. 93407.
}

riod and flight duration of western cherry fruit fly in Utah and Washington for IPM programs on tart cherry and sweet cherry (Prunus avium L.), respectively. In addition, we investigated the preoviposition period of flies in six orchards during 1987-1989.

\section{Materials and Methods}

The flight period of western cherry fruit fly was determined in northern Utah using Pherocon AM traps (Trece, Inc., Salinas, Calif.) placed in either backyard or abandoned orchards of tart cherry trees. Previous studies (Frick 1952, Frick et al. 1954) have shown that trap catch is a good predictor of first fly emergence and oviposition. Traps were placed in the orchards (Table 1) during the last two weeks of May and checked at least twice weekly throughout the season. Traps were replaced at weekly intervals except during the 1987-1989 seasons when an external ammonium carbonate lure was added to the trap to increase trap longevity (Jones 1988). During the 1987-1989 seasons, traps were replaced when they became dirty (about every $2-3 \mathrm{wk}$ ). Nearby host plants in the Utah locations were entirely tart or sweet cherries, and migration from nearby locations was possible because the areas trapped had been subdivided from large orchards and homeowners frequently kept some of the orchard trees for personal use. None of the orchards trapped were harvested during the experiments.

During the trapping period, the sex of flies was recorded and all flies were removed from the traps and placed in a $10 \%$ glycerol-alcohol solution for later dissection to determine degree of ovarian maturity. Female flies were classed as immature (ovar- 
Table 1. Summary of data collection sites and western cherry fruit fly emergence $1982-1989$

\begin{tabular}{|c|c|c|c|c|c|c|c|}
\hline Year & Location & Date first fly & $\begin{array}{c}\text { Date peak fly } \\
\text { catch }\end{array}$ & Date last fly & $\begin{array}{c}\text { Date last } \\
\text { immature female }\end{array}$ & $\begin{array}{l}\text { No. collect- } \\
\text { ed }\end{array}$ & Orchard type \\
\hline \multicolumn{8}{|c|}{ Cache County; Utah } \\
\hline 1984 & Hansen & 18 June & 4 July & 28 August & - & 688 & Home \\
\hline 1987 & Matthews & 8 June & $6 \mathrm{July}$ & 24 August & 14 August & 2,911 & Abandoned \\
\hline 1988 & Hansen & 6 June & 22 June & 9 September & 9 September & 2,972 & Home \\
\hline $1989^{a}$ & Gordon & 31 May & 19 June & 7 August & 3 July & 459 & Abandoned \\
\hline Average & & 9 June & 30 June & 24 August & 12 August & & \\
\hline \multicolumn{8}{|c|}{ Chelan County, Washington } \\
\hline 1982 & MoPhail & 8 June & 30 June & 4 August & - & 512 & Abandoned \\
\hline 1983 & Kenna & 3 June & 30 June & 4 August & - & 1,332 & Home \\
\hline
\end{tabular}

${ }^{a}$ Box Elder County, Utah.

ioles small and underdeveloped) or mature (ovarioles filling the abdomen).

Methods used in Chelan County, Washington, were similar, except that standard Pherocon AM traps were not supplemented with an external ammonium carbonate lure and only sweet cherries were sampled. Traps were checked at approximately weekly intervals. Ovary maturity data were only available from the 1988 site. Hosts nearby consisted only of sweet cherries. The monitored trees were not harvested during the experiments.

In Utah, temperature data were collected from the monitored orchard (1988-1989) or from the nearest NOAA weather station (1983-1987). The accuracy of the NOAA weather station was verified by placing data loggers in these locations in 1988 and 1989 and comparing degree-day (DD) accumulations between the data loggers and the weather stations. Using this method, differences in DD accumulations between March 1 and August 27 for the Matthews orchard did not exceed 60 DD and the DD accumulations were not modified. However, DD accumulations from the Hansen location were $\approx 1.1$ times higher throughout the season and thus were corrected by this value; this temperature difference was similar to that observed in 1983 by Davis (unpublished) using an on-site hygrothermograph. Temperature data for Washington were obtained from the NOAA weather station on the Tree Fruit Research Center in Wenatchee. Orchards monitored in Washington were all within four miles of the weather station. The equations of Baskerville \& Emin (1969) were used to calculate degree-days beginning 1 March using a lower threshold of $5^{\circ} \mathrm{C}$ (AliNiazee 1976, 1979) and no upper threshold. AliNiazee (1976) was the first to use $5^{\circ} \mathrm{C}$ as the base threshold. Van Kirk \& AliNiazee (1981) estimated $8.3^{\circ} \mathrm{C}$ as the most accurate threshold, but suggested that $5^{\circ} \mathrm{C}$ would not be an inappropriate choice. We used the $5^{\circ} \mathrm{C}$ threshold so that direct comparison of degree-day accumulations for first flies observed between our studies and AliNiazee's would be possible.
Emergence curves were constructed by plotting cumulative percentage of trap catch versus degreedays. Data from all locations were overlaid on the same graph to determine the degree of synchrony between locations and years.

The Erlang density distribution (Hastings \& Peacock 1974) was used to predict the composite emergence curve because it is the basis for the PETE models (Croft et al. 1978) that are commonly used to predict the phenology of deciduous fruit insects. This distribution is defined by a scale factor (Del) which is the average length of stage in degree-days and $\kappa$, which is an integer that specifies the shape of the curve. The shape of the distribution can vary from an exponential $(\kappa=1)$ to a normal curve $(\kappa=$ $\infty)$. The equation for the distribution is:

$$
p(\tau)=\left[(\alpha \kappa)^{\kappa} \tau^{(\kappa-1)} \exp (-\kappa \alpha \tau)\right] /(\kappa-1) !
$$

where $p(\tau)$ is the probability of emerging at time $(\tau)$ and $\alpha=\mathrm{Del}^{-1}$. The fit of the model was assessed for emergence between 2 and $92 \%$ using indifference bands of $5 \mathrm{~d}$ early and $5 \mathrm{~d}$ late as described by Welch et al. (1981).

\section{Results}

In Utah, western cherry fruit fly adults were first trapped between 31 May (1989) and 18 June (1984) with an average first trapping date of 9 June (Table 1). The last flies were captured from 7 August (1989) to 9 September (1988) with the average last trapping date of 24 August. The first flies were caught in Washington between 24 May (1988) and 8 June (1982) with the average first trapping date of 2 June. The last fly captures occurred between 1 and 4 August with the average date of 2 August. This is similar to the time of last trap catch reported by Frick et al. (1954) in Prosser, Washington. Peak trap catch in Utah tended to be $2-3 \mathrm{wk}$ before tart cherry harvest, whereas in Washington, it occurred within the sweet cherry harvest period. This 2-3 wk period is about the difference between harvest 


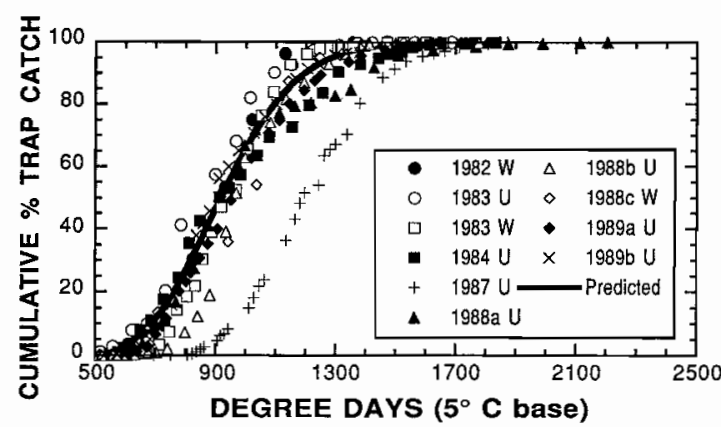

Fig. 1. Relationship between cumulative percentage of trap catch at various locations in Utah and Washington using the Erlang distribution function. U, Utah data, W, Washington data.

dates of sweet and tart cherries in Utah and Washington.

Female flies tended to be caught first in all but one of the orchards where sex ratio information was available. An early female-biased sex ratio was usually followed by a period when about equal numbers of each sex were caught, and then by a decline in the percentage of females caught late in the season. However, the sex ratios in the early and late flight periods may be deceptive because of the low numbers of flies caught at those times. When the total numbers of flies caught at each location were examined, the sex ratios were $39.7,54.6,56.0$, $45.3,28.5$, and $23.7 \%$ female with an overall average of $43.8 \%$ female $(n=7,907)$. This male bias in trap catch is similar to that reported by Frick et al. (1954), who found that the sex ratio on yellow cards baited with ammonium carbonate varied from $41.2 \%$ female to $48.7 \%$ female and was virtually identical to that observed using emergence cages in the same location. The strongly male-biased ratios in the last two orchards occurred where the fewest flies were collected.

On a degree-day scale, the first trap catch varied from 518 to $645 \mathrm{DD}(573 \pm 19.0, \bar{x} \pm \mathrm{SEM})$ in Utah and from 526 to $670 \mathrm{DD}(592 \pm 42.1)$ in Washington. This is $\approx 100 \mathrm{DD}$ later than AliNiazee (1979) observed in Oregon (468 \pm 19.9 DD). When the cumulative percentage emergence curves were plotted on a common degree-day scale (Fig. 1), there was only one data set (Utah, 1987) that was clearly outside the general sigmoid emergence curve. There were no abnormalities or conditions associated with this orchard (irrigation, spraying, etc.) that we are aware of that could explain the deviation from the generalized curve. This may therefore reflect the inherent variability possible in emergence when flies are exposed to different overwintering conditions (Brown \& AliNiazee 1977), or an unreported pesticide treatment of the abandoned orchard. We do not feel that migration from other sources nearby was responsible; Frick et al. (1954) showed dispersal up to $\approx 190 \mathrm{~m}$ was possible, but generally was quite rare over $42 \mathrm{~m}$. This would

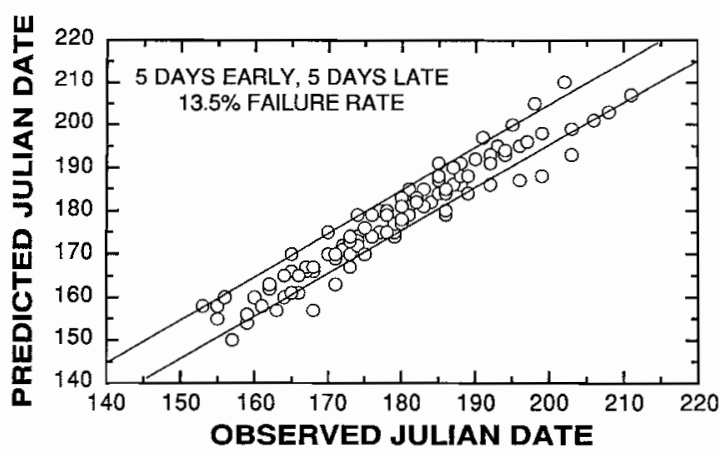

Fig. 2. Indifference band validation plot of the cumulative percentage of trap catch (2-92\%) from Utah and Washington using indifference bands of $5 \mathrm{~d}$ early, $5 \mathrm{~d}$ late.

limit the numbers caught to considerably less than the 2,911 flies caught in this location.

An Erlang distribution with Del $=933$ and $\kappa=$ 22 was fit to the entire data set minus the 1987 data (Fig. 1). Indifference band validation showed the model failure rate was $13.5 \%$ when the 1987 data were omitted (Fig. 2).

The phenology of ovarian maturity was predicted using an Erlang distribution with $\mathrm{Del}=1009$ and $\kappa=25$ (Fig. 3). The ovarian maturity curve is approximately parallel and shifted to the right 89 DD from the emergence curve. Under field conditions in both Utah and Washington during midJuly, this allows growers 5-6 d between emergence and when flies are physiologically able to oviposit.

\section{Diseussion}

This study shows that the phenology of populations from Utah and Washington can be predicted using a single model. This is in contrast to the apple maggot populations from various parts of the United States and Canada that Jones et al. (1989) found emerged up to 402 DD apart. This may be the result of a closer association of the western cherry fruit fly to its host plants (Boller \& Bush 1974), the similarity in climate between Utah

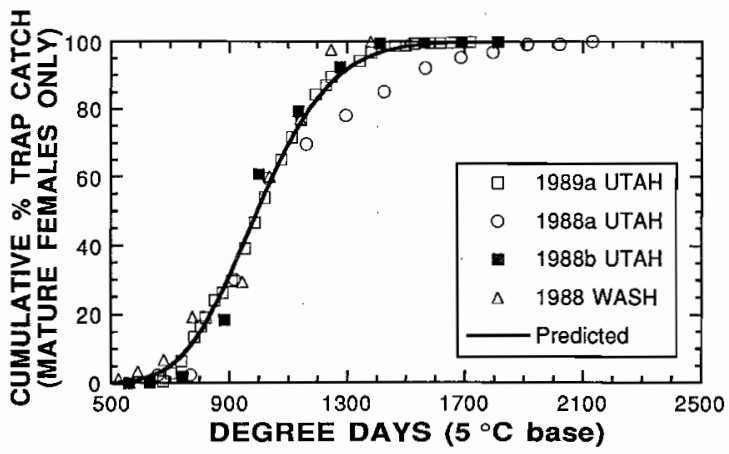

Fig. 3. Relationship between cumulative percentage of trap catch for mature females only and predicted maturation using the Erlang distribution function. 
and Washington cherry-growing areas, or a close genetic similarity between flies in both areas.

Our model predicts that fly emergence occurs much later than predicted by the model of AliNiazee (1979). For example, AliNiazee (1979) predicts first emergence would occur at $462 \mathrm{DD}$, whereas our model predicts first trap catch at 573 DD. Given the fact that yellow traps baited with ammonium carbonate generally catch flies $0-4 \mathrm{~d}$ before they are observed in emergence cages (Frick 1952, Frick et al. 1954, AliNiazee 1978), we expect that the differences in degree-day are real; if they were solely related to emergence cage compared to aerial trapping, the degree day accumulations in Utah \& Washington should have been $\approx 100 \mathrm{DD}$ less than that observed in Oregon instead of the reverse. The differences may reflect different irrigation methods (see Smith \& Jones [1991] for changes in emergence pattern of $R$. pomonella at different times of increased soil moisture), region differences in populations, or placement of the emergence cages in warmer, nonrepresentative sections of the orchard.

Capture of sexually immature flies near the end of the flight period (Table 1) may indicate a very limited second generation (Frick et al. [1954] found that $0.01-1.1 \%$ of flies can emerge without undergoing diapause), or more likely, it reflects the fact that emergence cage information underestimates the time required for emergence in the field. Such underestimation is probably caused by the limited population sizes under emergence cages and the use of only a few emergence cages per orchard. In addition, because environmental conditions (e.g., aspect, ground cover, and canopy development) within the orchards vary, degree-day accumulations experienced by individual pupae throughout the orchard probably differ considerably. Emergence cages cover a limited area and pupae probably do not experience this same sort of variation in heat accumulation as do the natural populations.

Models based only on emergence cage studies may lead to erroneous pest management decisions. Frick (1952) and Frick et al. (1954) found that adult activity as measured by trap catch was more closely correlated with oviposition than were emergence cage data. In Utah tart cherry orchards, where several pounds of cherries suitable for western cherry fruit fly development are left unprotected on each tree after mechanical harvest (V.P.J., unpublished), trap catch data show that these cherries are available to late-emerging flies. Therefore, in orchards with high populations, a postharvest spray of a pesticide with long residual may be used to cut next year's population pressure dramatically. This same tactic would be applicable to Washington growers who occasionally stop harvest because of the low market prices for later maturing varieties or because rain or hail cracks or bruises the cherries.

A degree-day model that predicts western cherry fruit fly capture on traps is a better indication of activity in the orchard and is more useful for man- agement decisions than a model that predicts emergence of flies from the soil. However, trap catch alone is not sufficient to indicate oviposition activity, even if flies on the trap are sexually mature. Messina et al. (1991) found that oviposition by western cherry fruit fly in tart cherries did not occur for $\leq 11 \mathrm{~d}$ after sexually mature flies were caught in the orchard and was closely related to fruit maturity as measured by the mean penetration resistance of the fruit skin. For the closely related apple maggot, Messina \& Jones (1990) found that the discrepancy between sexual maturity and oviposition on black hawthorn, Crataegus douglasii Lindl., was even greater, with a delay of $\leq 45 \mathrm{~d}$ between the capture of the first sexually mature fly and when fruit infestations were detected. Those studies suggest that fruit infestation is dependent upon fruit ripeness and that a phenology model of the emergence of an insect (or even its sexual maturity) is only a single component in the management system. The importance of the models should therefore be considered to be primarily in determining when monitoring should begin, when the earliest possible time of sexual maturity occurs, and in helping to develop pest control systems when multispecies complexes are present.

\section{Acknowledgment}

The authors thank Deb Bumpus, Lynn Forlow, Charlie Grant, Sheri Smith, Brett Cambell, Sandy Hanson, and Matt Peach for providing technical assistance during this study. The reviews of two anonymous reviewers contributed much to this manuscript. This work was supported in part by a grant from the Utah Agricultural Experiment Station at Logan. This is paper 4026 of the Utah Agricultural Experiment Station.

\section{References Cited}

AliNiazee, M. T. 1976. Thermal unit requirements for determining adult emergence of the western cherry fruit fly in the Willamette Valley of Oregon. Environ. Entomol. 5: 397-402.

1978. The western cherry fruitfly, Rhagoletis indifferens (Diptera: Tephritidae). 3. Developing a management program by utilizing attractant traps as monitoring devices. Can. Entomol. 110: 1133-1139.

1979. A computerized phenology model for predicting biological events of Rhagoletis indifferens. Can. Entomol. 111: 1101-1109.

Baskerville, G. L. \& P. Emin. 1969. Rapid estimation of heat accumulation from maximum and minimum temperatures. Ecology 50: 514-516.

Boller, E. F. \& G. L. Bush. 1974. Evidence for genetic variation in populations of the European cherry fruit fly, Rhagoletis cerasi (Diptera: Tephritidae) based on physiological parameters and hybridization experiments. Entomol. Exp. Appl. 17: 279-293.

Brown, R. D. \& M. T. AliNiazee. 1977. Synchronization of adult emergence of the western cherry fruit fly in the laboratory. Ann. Entomol. Soc. Am. 70; 678-680.

Croft, B. A., S. M. Weleh, J. F. Brunner, \& M. F. Michels. 1978. PETE: an extension phenology 
modeling system for management of multi-species. pest complex. Environ. Entomol. 7: 487-494.

Davis, D. W. \& V. P. Jones. 1986. Understanding the apple maggot. Utah Sci. 47: 94-97.

Frick, K. E. 1952. Determining emergence of the cherry fruit fly with ammonium carbonate bait traps. J. Econ. Entomol. 45: 262-263.

Friek, K. E., H. G. Simkover \& H. S. Telford. 1954. Bionomics of the cherry fruit flies in eastern Washington. Tech. Bull. Wash. Agric. Exp. Stn. No. 13.

Hastings, N.A.J. \& J. B. Peacock. 1974. Statistical Distributions. Wiley, New York.

Jones, V. P. 1988. Longevity of apple maggot (Diptera: Tephritidae) lures under laboratory and field conditions in Utah. Environ. Entomol. 17: 704-708.

Jones, V. P. \& D. W. Davis. 1989. Evaluation of traps for apple maggot populations associated with cherry and hawthorn in Utah. Environ. Entomol. 18: 521525.

Jones, V. P., D. W. Davis, S. L. Smith \& D. B. Allred. 1989. Phenology of apple maggot associated with cherry and hawthorn in Utah. J. Econ. Entomol. 82: 788-792.

Messina, F. J. \& V. P. Jones. 1990. Relationship between fruit phenology and infestation by the apple maggot (Diptera: Tephritidae) in Utah. Ann. Entomol. Soc. Am. 83: 742-752.

Messina, F. J., D. G. Alston, \& V. P. Jones. 1991. Oviposition by the western cherry fruit fly (Diptera: Tephritidae) in relation to host development. J. Kans. Entomol. Soc. (in press).

van Kirk, J. R. \& M. T. AliNiazee. 1981. Determining low-temperature threshold for pupal development of the western cherry fruit fly for use in phenology models. Environ. Entomol, 10: 968-971.

Smith, S. L. \& V. P. Jones. 1991. Alteration of apple maggot (Diptera: Tephritidae) emergence by cold period duration and rain. Environ. Entomol. 20: 4447.

Stark, S. B. \& M. T. AliNiazee. 1982. Model of postdiapause development in the western cherry fruit fly. Environ. Entomol. 11: 471-474.

Welch, S. M., B. A. Croft \& M. F. Michels. 1981. Validation of pest management models. Environ. Entomol. 10: 425-432.

Received for publication 27 July 1990; accepted 2 April 1991. 